\section{A diversidade ética e política na garantia e fruição do direito à saúde nos municípios brasileiros da linha da fronteira do MERCOSUL}

\author{
Ethical and political diversity in the right to \\ health care in Brazilian municipalities along the \\ MERCOSUR border
}

\footnotetext{
${ }^{1}$ Escola de Serviço Social, Universidade Católica de Pelotas, Pelotas, Brasil. 2 Universidade Federal de Santa Catarina, Florianópolis, Brasil. 3 Programa de Pós-Graduação em Serviço Social, Pontifícia Universidade Católica do Rio Grande do Sul, Porto Alegre, Brasil.

Correspondência V. M. R. Nogueira Escola de Serviço Social Universidade Católica de Pelotas. Rua Félix da Cunha 412, Pelotas, RS 96010-000, Brasil. vera.nogueira@pesquisador. cnpq.br
}

\begin{abstract}
This article presents the results of a study in Brazilian municipalities along the border with the other Southern Cone Common Market (MERCOSUR) countries, identifying health care patterns and showing ethical and political diversity in the guarantee and use of the right to health care, characterizing demands on (and responses by) local health systems. The main variable was whether non-Brazilians had access to Brazilian health services. Data were collected using forms in municipalities with more than 10 thousand inhabitants, field diaries, meetings, and interviews. The definition of the right to health care varied greatly, indicating lack of common ethical and political principles and weak institutionality, with incapacity to absorb the demand by non-Brazilian patients. Agreements between the respective Federal governments of MERCOSUR countries had failed to reach the local level and were ignored by local health services managers and professionals. The foreign population remains uncertain about receiving care. In Brazil, the lack of uniform standards of care lead to ad hoc personal decisions by health services managers and professionals, thus hindering integrated action.
\end{abstract}

Right to Health; Health Services Needs and Demand; Border Areas; Health Policy
Vera Maria Ribeiro Nogueira 1,2

Keli Regina Dal Prá 3

Sabrina Fermiano 2

\section{Introdução}

Este artigo apresenta parte das conclusões do estudo, realizado na linha da fronteira entre o Brasil e os demais países que integram o MERCOSUL, que ocorreu entre 2003 e 2005, com financiamento do Conselho Nacional de Desenvolvimento Científico e Tecnológico (CNPq) e apoio logístico da Secretaria Executiva da Articulação Internacional do Estado de Santa Catarina, Brasil.

Tem como proposta identificar os perfis distintos de atenção que evidenciam a diversidade ética e política existente entre os municípios da linha da fronteira, na garantia e fruição do direito à saúde a partir da caracterização das demandas por ações e serviços de saúde e das respostas oferecidas pelos sistemas locais de saúde. Aborda a situação do direito à saúde na região, utilizando, como marco de referência, a saúde como um direito universal, o que implica ultrapassar os usuais limites territoriais de cada uma das nações. Parte-se da premissa de que os elementos constitutivos dos processos de regionalização e globalização ocorridos nos últimos anos exigem a revisão da concepção de direito social vinculado ao Estado-nação, espraiando-se para o nível internacional.

$\mathrm{O}$ direito à saúde, na perspectiva adotada, pressupõe, ainda, sua articulação com as condições reais de factibilidade e viabilidade, tendo como suposto que as formas dos ordenamentos econômicos e políticos incidem diretamente so- 
bre esse direito, expressando-se de formas distintas de região para região.

A base empírica que subsidiou a análise foi a garantia ou não do acesso às ações e aos serviços de saúde do Sistema Único de Saúde (SUS) pelos usuários não brasileiros, buscando atingir os seguintes objetivos: caracterizar o perfil da demanda para as ações e serviços de saúde e para o atendimento sócio-assistencial correlato, buscando evidências sobre o trânsito populacional interfronteiras; aprofundar a reflexão sobre como e sob quais perspectivas ético-políticas o direito à saúde vem se consolidando nos países do MERCOSUL; produzir conhecimento que subsidie as decisões quanto à proteção social da saúde na região da fronteira do MERCOSUL, buscando favorecer o alcance da integração social para além da unicamente econômica.

O artigo está organizado em três partes, sendo a primeira uma breve indicação das referências metodológicas e analíticas, incluindo os principais resultados quantitativos encontrados. Na segunda parte, discutem-se os perfis de demanda e acesso ao SUS pelos usuários não brasileiros, e, na terceira e última parte, trata-se de evidenciar como o direito à saúde na região da fronteira é uma questão alheia às normatizações do SUS do Brasil e distante dos documentos legais que organizam o trânsito interfronteiras.

\section{Indicações de ordem metodológica}

Para a efetivação do estudo, foi necessário garantir a apropriação prévia de questões relativas ao entorno da atenção à saúde em áreas de fronteira. Estabeleceu-se, inicialmente, um plano de estudos que considerasse os conceitos que serviriam como parâmetros analíticos para as definições metodológicas e analíticas posteriores, como território, territorialidade, zona de fronteira, faixa de fronteira e linha de fronteira. Essa revisão possibilitou adotar a concepção de território como um espaço que tende a marcar a exclusão, sendo reducionista sua apreensão unicamente como uma determinação jurídico-administrativa. O território “...é produto de processos de controle, dominação elou apropriação do espaço físico por agentes estatais e não estatais" 1 (p. 62). Feldmann ${ }^{1}$ aponta que o território é pensado como o espaço controlado por certo tipo de poder, sendo delimitado e definido a partir desse ideário. A noção de territorialidade, antagonicamente, aponta para processos relacionados às influências, ao controle do uso social do espaço físico, podendo ter um caráter inclusivo, “...incorporando novos e velhos espaços de forma oportunista elou seletiva, não separando quem está 'dentro' de quem está fora” 1 (p. 62). A própria concepção de espaço foi revisada, passando a ser visto como uma construção feita por atores que configuram seu entorno de acordo com suas visões sócio-políticas e culturais, que interferem sobremaneira na representação sobre o objeto de estudo em questão.

Para caracterizar o trânsito interfronteiras, foi relevante a clareza conceitual entre linha de fronteira, faixa e zona de fronteira. Enquanto a Faixa de Fronteira é definida legalmente, associada aos limites territoriais do poder estatal, a concepção de Zona de Fronteira aponta para um “...espaço de interação, uma paisagem específica, com espaço social transitivo, composto por diferenças oriundas da presença do limite internacional, $e$ por fluxos e interações transfronteiriças, cuja territorialização mais evoluída é a das cidades gêmeas" 2 (p. 21). É o espaço onde são testadas as políticas públicas de integração e cooperação, um microcosmo das diferenças de expectativas e transações entre os níveis local, regional e internacional. Ou, na acepção de Gonzáles 3: " $L a$ frontera se concibe como signo visible de la existencia del Estado: el territorio termina en la frontera, donde los poderes del Estado se encuentran 'monumentalmente inscriptos'”

Em relação à coleta dos dados, foram utilizados quatro instrumentos: levantamentos em base de dados oficiais sobre indicadores municipais de saúde; entrevistas semi-estruturadas com informantes-chave, considerados assim os gestores, profissionais e conselheiros de saúde nos municípios-pólo; formulários aplicados nos municípios; registro de observações em diário de campo e reuniões com profissionais.

As reuniões e entrevistas ocorreram entre outubro de 2004 e junho de 2005, nos seguintes municípios: Uruguaiana, São Borja, Jaguarão e Santana do Livramento, no Rio Grande do Sul; no Paraná, em Foz do Iguaçu e Guaíra; e, em Santa Catarina, em Dionísio Cerqueira. Os formulários e as observações tiveram como foco os 26 municípios brasileiros situados na linha de fronteira com mais de 10 mil habitantes ou que tivessem sido indicados no estudo preliminar como pontos estratégicos na linha de fronteira com relação ao fluxo de estrangeiros ou ainda que evidenciassem algum aspecto particular relacionado com a harmonização dos sistemas de saúde. São eles: São Borja, Santana do Livramento, Uruguaiana, Jaguarão, Bagé, Dom Pedrito, Chuí, Quaraí, Itaqui, Crissiumal, Porto Xavier e Santa Vitória do Palmar, no Rio Grande do Sul; Itapiranga, São José do Cedro, Guaraciaba e Dionísio Cerqueira, em Santa Catarina; e Barracão, Santa Helena, Missal, Planalto, Santo Antônio do Sudoeste, Capanema, Marechal Cândido Rondon, 
São Miguel do Iguaçu, Foz do Iguaçu e Guaíra, no Paraná.

Os formulários foram respondidos por profissionais com atuação direta junto aos usuários e que, em tese, poderiam traduzir a demanda e a resposta oferecida a esses usuários pelo sistema de saúde. Tem-se clareza de que as respostas são relativas às percepções que os profissionais têm, as quais, evidentemente, são determinadas por uma série de fatores e podem não representar exatamente a situação real. A triangulação de instrumentos procurou minimizar esse fato. Dos 212 formulários, $32 \%$ foram aplicados na fronteira com a Argentina; $17 \%$, na fronteira com o Paraguai; $21 \%$, na fronteira com o Uruguai; e 28\%, na fronteira Argentina/Paraguai (Foz do Iguaçu). Houve preocupação em diversificar os locais de aplicação dos formulários pelo tipo de atendimento prestado. Por esse critério, aplicaram-se $2,9 \%$ formulários em serviços de pronto atendimento, $22,6 \%$ em centros especializados, $52,2 \%$ em postos e unidades básicas de saúde, 1,9\% em centro de atendimento psicossocial, 0,9\% em núcleo de atendimento psicossocial, $17,7 \%$ em hospitais gerais e $1,4 \%$ em hospitais especializados. Foi pesquisada unicamente a rede pública e/ou conveniada de atenção à saúde; e a amostra, em cada município, foi definida em relação à rede instalada.

Paralelamente, foi efetivada a revisão da legislação sobre o direito social do trabalhador no MERCOSUL, com o levantamento dos acordos, leis e portarias assinadas bilateralmente e trilateralmente, os quais são analisados em uma das produções teóricas da pesquisa. Igualmente, foram identificados os acordos informais estabelecidos entre os municípios e províncias; a identificação dos pactos fundamentados nos direitos humanos e no Estatuto do Estrangeiro; a atualização das políticas nacionais de saúde com foco na fronteira. Importa mencionar que essas atividades tiveram continuidade ao longo do desenvolvimento do projeto, sendo, entretanto, marcantes nesse período.

No que se refere à sistematização e organização dos dados, alguns pontos merecem destaque, e o mais significativo refere-se à fragilidade no registro das informações quanto à demanda e ao atendimento de usuários estrangeiros.

Com relação ao panorama físico da linha de fronteira estudada, essa tem uma extensão de $2.200 \mathrm{~km}$ (Instituto Brasileiro de Geografia e Estatística. Cidades. http://www.ibge.gov.br, acessado em 01/Jul/2005). Foi caracterizada como Arco Sul em recente estudo publicado pelo Ministério da Integração Nacional 2 e inclui as fronteiras dos estados do Paraná, Santa Catarina e Rio Grande do Sul. É integrada por 57 municípios, sendo dez na fronteira com o Uruguai, 38 municípios na fronteira com a Argentina e nove com o Paraguai. Divide-se em três sub-regiões: o portal do Paraná, os vales sulinos e o segmento da mesorregião da metade sul do Rio Grande do Sul conhecido como a campanha gaúcha 2 .

Destacam-se, na linha de fronteira, as cidades gêmeas, que apresentam certas simetrias e um potencial de integração econômica e cultural distinto das demais cidades. Igualmente, são áreas onde se condensam alguns dos problemas próprios de áreas limítrofes internacionais que sinalizam efeitos imediatos nas condições de cidadania.

Em relação à dimensão sócio-econômica, constatou-se que a renda média mensal da região oscila entre R\$ 300 e R \$ 400 em 52\% dos municípios estudados, e o Índice de Desenvolvimento Humano (IDH) desses municípios é relativamente estável, oscilando entre 0,743 e 0,832.

Na dimensão cultural, a influência brasileira ocorre desigualmente, sendo mais intensa em alguns Estados do que em outros. Os movimentos migratórios entre Brasil, Argentina e Uruguai são fracos e estabilizados, destacando um forte movimento pendular apenas nas cidades gêmeas. Em relação ao Paraguai, há preponderância da influência cultural brasileira e alta permeabilidade e porosidade em redes econômicas e sociais 2 .

Os dados quantitativos foram analisados, primeiramente, a partir da perspectiva de cada país fronteiriço, uma vez que as interações têm uma determinação cultural e histórica definida pelo Estado-nação. Para fins analíticos, desagregouse, das demais linhas fronteiriças, a região denominada de Tríplice Fronteira, constituída pelas cidades de Cidade do Leste, Porto Iguaçu e Foz do Iguaçu, devido à sua singularidade, identificada desde os primeiros momentos do estudo.

As informações contidas nos diários de campo dos pesquisadores e os relatórios das reuniões realizadas com profissionais e gestores da região foram sistematizados obedecendo às categorias construídas a partir dos objetivos previstos.

\section{Perfis de demanda e acesso ao SUS pelos usuários não brasileiros}

Em relação às formas de entrada no sistema utilizadas pelos brasileiros e estrangeiros na região estudada, do total dos formulários aplicados, estão, em primeiro lugar, os postos de saúde $(23,82 \%)$, seguidos dos serviços de emergência (21,8\%), equipe do Programa Saúde da Família (PSF - 15,1\%), centro especializado (12\%), plantão social $(13,9 \%)$ e outras $(10,1 \%)$. Os encaminhamentos foram realizados em ordem prioritá- 
ria pelos médicos $(34,6 \%)$, seguidos dos agentes de saúde $(29 \%)$, conselho tutelar (16\%), voluntariado (6\%), políticos (5\%), Organizações Não Governamentais (ONGs - 1,6\%) e outros $(4,4 \%)$. Quando se analisam os outros encaminhamentos, destacam-se as inter-relações entre demandas em saúde e exclusão social, na medida em que as menções reiteradas são presídios, penitenciária, assistentes sociais, Ministério Público, Vara da Infância e Juventude, Associação de Pais e Amigos dos Excepcionais (APAE), Corpo de Bombeiros, padres e pastores. Dois insólitos encaminhamentos são mencionados - um realizado pelo cônsul brasileiro no Paraguai e outro por curandeiros e benzedeiras.

Quanto aos recursos públicos de saúde brasileiros, disponíveis ao longo da linha da fronteira, predominam majoritariamente os hospitais privados conveniados com o SUS, e, em dois municípios, não existe tal recurso para atenção à saúde. A implantação do PSF vem se constituindo em uma barreira para o acesso dos estrangeiros ao sistema, devido à exigência de adstrição dos usuários, ocasionando ainda um deslocamento da demanda das unidades básicas para os centros de especialidades, onde não há exigência de documentação. Em Santa Catarina, a cidade considerada como pólo de entrada é Dionísio Cerqueira, que conta com um pequeno hospital. Os casos de maior complexidade são encaminhados para São Miguel do Oeste e Chapecó. No Paraná, a cidade de Foz do Iguaçu é referência para a região, com uma rede de serviços extensa, com recurso para atendimento de alta e média complexidades. Em 12 municípios, mais de 80\% da população residem na área urbana. As observações dirigidas realizadas pelos pesquisadores confirmam que os usuários das unidades básicas de saúde são pessoas empobrecidas e com uma face de sofrimento que denota a exclusão social e econômica a que são submetidas.

Os resultados quantitativos foram ainda analisados em relação às seguintes variáveis: existência e percentual de demanda e atendimento; acesso e transporte mais utilizado; razão da demanda; ações e serviços mais procurados; interferência de influências culturais no atendimento à saúde; recursos financeiros, integração de políticas e direito ao atendimento. Identificou-se que, ao longo da linha da fronteira, em 92,9\% das unidades de saúde pesquisadas, os respondentes apontaram a existência de demanda para atendimento de estrangeiros; e, em apenas 7\%, a referência é ambígua, pois, em um município, um respondente indicou que não havia, e outro mencionou a existência de estrangeiros demandando atenção à saúde. No tocante à condição de acessibilidade, essa é facilitada ou dificultada pelo tipo de acesso e o transporte mais utilizado. No caso estudado, verificou-se que, devido ao tipo de fronteira física existente, a entrada no Brasil ocorre preferencialmente por ponte e balsa. Em alguns municípios, embora exista transporte coletivo de um país para o outro, muitos usuários chegam ao serviço fazendo a travessia a pé, pelas pontes.

O número de estrangeiros que busca atendimento no SUS é relativamente uniforme ao longo da fronteira, situando-se entre $0 \%$ e $10 \%$ em $61,3 \%$ das menções. Já os que se situam entre $11 \%$ e $20 \%$ perfazem $12,3 \%$ das referências; entre $21 \%$ e $30 \%$ correspondem a $8,9 \%$ das referências; e entre $31 \%$ e $40 \%$, a 7,4\% das referências. Quando se analisa particularmente cada país, verificase que, entre os $31,1 \%$ dos usuários originários da Argentina, $26,2 \%$ ficam entre $0 \%$ e $10 \%$ da demanda. No Uruguai, $22 \%$ das referências ficam entre 0 e $10 \%$, o que caracteriza uma demanda reduzida. Em relação ao percentual de estrangeiros que são atendidos, a situação se particulariza em cada município, sendo as freqüências maiores obtidas em Foz do Iguaçu $(28,2 \%)$, Guaíra $(8,4 \%)$, Santana do Livramento $(7,4 \%)$, São Borja e Uruguaiana $(6,4 \%)$, Santa Helena (5,4\%), Missal (4,9\%), Quaraí e Bagé (3,4\%), e Jaguarão (2,9\%). Nos demais municípios, a demanda, quando referida, oscila entre $0,99 \%$ e $1,4 \%$. Quanto às razões para a procura do atendimento no Brasil, em uma ordem hierárquica, a gratuidade do sistema foi o motivo mais citado (15,9\%), seguido pela proximidade da residência (13,3\%), qualidade dos serviços (12\%), existência de amigos ou parentes no local $(10,7 \%)$, precariedade dos serviços nos países de origem (10,6\%) e inexistência do serviço de saúde no próprio país $(9,2 \%)$, e facilidade de entrada no sistema $(8,7 \%)$.

Com relação aos serviços e ações de saúde que mais atraem os usuários não residentes no Brasil, destacam-se os atendimentos médicos, citados com uma freqüência similar nos três países e na Tríplice Fronteira. Os medicamentos se situam como a segunda atração para o ingresso no sistema, com a maior freqüência, entretanto, na região da Tríplice Fronteira. Em terceiro lugar, são as vacinas que mobilizam a vinda dos usuários estrangeiros. Confirmando dados anteriores, identificam-se, na região da Tríplice Fronteira, dois aspectos relacionados ao fator pobreza que atraem os usuários de outros países: um deles corresponde aos encaminhamentos para outros serviços sociais, utilizando-se a entrada no sistema de saúde como uma ponte para obter esses outros serviços. A busca pela legalização da situação no Brasil igualmente reflete a precariedade e a exclusão social na região. Chama a atenção o fato de que os aspectos culturais interferem 
relativamente pouco na interação entre os usuários estrangeiros e os serviços de saúde. Entre os 212 formulários aplicados, somente 31 fazem referência a algum tipo de influência cultural. A única ressalva acontece na Tríplice Fronteira, onde um dos motivos relatados para o fato é o alto número de usuários indígenas que habitam a região e o uso do Guarani, língua oficial do Paraguai e falada por mais da metade de sua população (Ministério de Salud Pública y Bienestar Social del Paraguay. Plano Nacional de Salud 20032008. http://www.mspbs.gov.py/planificacion/ polsalud.htm, acessado em 01/Jun/2005). Na mesma região, são referenciados como outros aspectos culturais os preconceitos contra os "brasiguaios", a religiosidade, a dificuldade de entender as rotinas burocráticas, os protocolos e as leis brasileiras, os hábitos, os costumes alimentares e higiênicos, o medo de não ser atendido, a crença na medicina natural.

Destaca-se a importância da gratuidade do sistema brasileiro na região da Tríplice Fronteira em relação à Argentina e ao Uruguai. Na fronteira com esses países, a qualidade do serviço oferecido, em lugar da gratuidade, aparece com destaque para a busca de atendimento no Brasil. A proximidade, que é um fator significativo para os usuários que procedem da Argentina, não é citada como tal para os que são originários do Paraguai e da Tríplice Fronteira. Uma dimensão a ser ressaltada entre as razões mais importantes para a busca do usuário estrangeiro na Tríplice Fronteira é a obtenção de vantagens que decorrem da aquisição da cidadania brasileira para os filhos. Esse fato é referido nas entrevistas e o foi também nas reuniões com profissionais que subsidiaram a construção do formulário. Inúmeras parturientes acorrem à cidade de Foz do Iguaçu para terem os filhos em território brasileiro, garantindo, assim, não só o ingresso no sistema de saúde, como as demais vantagens decorrentes da cidadania brasileira. A precariedade dos serviços ou a inexistência de qualquer serviço de saúde no país e região onde vivem e a atenção integral, mencionadas com freqüência relativamente elevada na região da Tríplice Fronteira, indicam a dimensão do problema para o sistema de saúde de Foz do Iguaçu.

A exigência de documentação pessoal não é uniforme ao longo da fronteira, seja para atendimento em atenção básica, seja ambulatorial. As equipes de PSF usualmente solicitam documentos, incluindo o comprovante de residência, bem como os municípios que estão fazendo o cadastramento dos habitantes e iniciando a implantação do Cartão SUS. Nos municípios onde tal cadastramento ocorre, o usuário estrangeiro, para ingresso no sistema, regulamenta sua situ- ação de acordo com as leis brasileiras ou busca estratégias para burlar a lei. A dificuldade para regularização de documentos pessoais, segundo os relatos, deve-se ao alto custo desses processos. A maioria das respostas aponta uma orientação por parte dos gestores em atender unicamente aos casos de urgência e emergência. Informações coletadas com os profissionais de saúde demonstraram que os estrangeiros são atendidos na rede de saúde, principalmente, no nível de atenção básica e ambulatorial, dentro da capacidade do município, não sendo registrados como estrangeiros.

Foram mencionados raros casos de usuários estrangeiros que conseguiram prosseguir com o tratamento de saúde de alta complexidade em outro município. Nessas situações, segundo os entrevistados, ficou comprovado, posteriormente, que houve algum tipo de falsificação de documentos. Sendo assim, quando um usuário estrangeiro necessita de atendimento de alta complexidade que tenha que ser fornecido fora do município fronteiriço, o atendimento é interrompido.

Na fronteira entre o Brasil e o Uruguai, não há referências, pelos profissionais entrevistados, sobre a Lei $n^{o}$. 907, de 21 de novembro de 2003 4, que prevê a igualdade de direitos em trabalho, residência, estudo e previdência aos 850 mil uruguaios e brasileiros que vivem a $20 \mathrm{~km}$ do limite entre os dois países. Igualmente, não há menção à Lei $n^{o}$. 6.815, de 19 de agosto de 1980, que define a situação jurídica do estrangeiro no Brasil 5 . Um dado significativo em termos de provisão de atenção refere-se à população "brasiguaia”: além do número, estimado em 350 mil pessoas, essa não possui documentos. Os emigrantes que entraram no Paraguai nos anos 70 geralmente não têm documentos. Por essa razão, existem famílias de indocumentados, cujos filhos não têm registro no Paraguai nem no Brasil. As estimativas é que $10 \%$ dos "brasiguaios" estejam nessa situação. Já entre as crianças, estima-se que $20 \%$ ou $30 \%$ não possuem certidão de nascimento ou outro documento que possibilite o acesso legal ao SUS.

No que se refere à integração das políticas, em geral, a maior parte dos profissionais que estão no atendimento direto com a população desconhece quaisquer medidas, acordos ou pactos que digam respeito a essa integração. Foram identificadas escassas referências ao MERCOSUL no aspecto econômico, político e jurídico. A integração, quando relatada, é sobre campanhas conjuntas de vacinação, que vêm sendo implementadas pelo Programa Vacinação nas Américas. Os Comitês de Fronteira não aparecem como fóruns consolidados para discussão de políticas de integração, não tendo sido mencionados pelos 
profissionais de saúde como órgãos que influenciem ou viabilizem a integração de políticas.

Confirmou-se que os gestores buscam solucionar problemas de escassez pela união informal com gestores locais de países vizinhos, conforme já havia sido apontado por Gallo ${ }^{6}$. Entretanto, em função de barreiras jurídico-institucionais e político-econômicas, essas ações não observam necessariamente sustentabilidade, qualidade ou racionalidade, ou seja, estabilidades institucionais que viabilizem sua transposição para o nível de políticas públicas com maior densidade.

\section{Direito à saúde: uma questão personalista e burocratizada}

As opiniões referentes ao grau e à amplitude do direito à saúde pelos não residentes ao SUS foram extremamente diversificadas entre os gestores, profissionais de saúde e conselheiros de saúde, com preponderância das respostas afirmativas. Entretanto, quando se questiona em quais casos o direito não é garantido, aparece alta incidência de respostas segundo as quais isso acontece nos casos de inexistência de documentação civil e comprovante de residência, seguida de tratamentos de alta complexidade e cirurgias eletivas, assistência farmacêutica, atendimento odontológico e medicamentos de uso contínuo. Aproximadamente, $35 \%$ das respostas indicam a não existência de direito garantido. Importa observar que a maior incidência de respostas nessa direção foi encontrada entre os profissionais situados na linha de fronteira com o Paraguai.

Os obstáculos se localizam na falta de documentos que comprovem a cidadania brasileira e sinalizam a urgência de políticas que dêem sustentação efetiva aos processos de integração no setor de saúde. Os gestores e profissionais de saúde ressaltam não estarem informados ou não tomarem conhecimento das discussões em escalões superiores do governo. Alertam para o peso causado aos municípios para arcar com os custos financeiros dos atendimentos aos usuários não residentes, sendo esse o fator primordial para a negação do direito. A orientação de não atendimento por parte dos gestores foi uma das respostas explicativas para a não garantia dos direitos por apenas 3\% dos respondentes. Parte das respostas contrárias à garantia do direito ao usuário não brasileiro é motivada por uma insuficiência do próprio sistema, que não atende, também, os brasileiros de forma satisfatória. Assim, parece não estar em jogo o fato de a pessoa ser estrangeira, mas essencialmente a debilidade das políticas de saúde brasileiras. Parte das explicações encontradas para o não atendimento sinaliza, ainda, motivações de ordem prática e até bastante pragmáticas, como a inexistência de equipamentos, a falta de recursos humanos, a insuficiência de vagas para consultas médicas, as filas, os horários não coincidentes, os atrasos nos repasses financeiros e a "burocracia brasileira". A não reciprocidade de atendimento em outros países igualmente é um dos argumentos para o não reconhecimento dos direitos à saúde dos estrangeiros não residentes.

Os respondentes que afirmam ser o direito efetivamente garantido em quase todos os casos apontam, como exemplos concretos, o atendimento às gestantes, as solicitações de vacinas, os atendimentos de urgência e emergência, os procedimentos de atenção básica, as consultas médicas e os casos de mordidas de cobras e outros animais. $\mathrm{O}$ direito de o usuário estrangeiro ser atendido é visto desde como um ato cristão até como um direito decorrente de igualdade, independente da origem, nacionalidade, cor e condição econômica. Paradoxalmente, sobressaem tanto a noção de cidadania vinculada à residência no Brasil e a forte crítica ao usuário que utiliza estratégias para inclusão no sistema, como práticas e estratégias de inserção dos cidadãos estrangeiros, por parte de brasileiros, que fogem à legalidade estabelecida.

Igualmente, a concepção de direito entre os profissionais não é unívoca. Identifica-se um continuum que parte da afirmação segundo a qual a cidadania social se vincula ao trabalho, determinada pela meritocracia de inserção ao mercado formal e assemelhando-se a um seguro social, até os que afirmam ser a cidadania social um direito universal, global e de responsabilidade dos gestores dos três níveis de governo, ultrapassando limites territoriais nacionais. No primeiro caso, a população empobrecida, que não contribui com o Sistema, não tem o status de cidadão.

Ainda em relação aos profissionais de saúde, a explicação para as estratégias de inclusão desenvolvidas pelos usuários estrangeiros toma a forma de uma censura ou de apoio, o que se relaciona à própria idéia de cidadania social e seus determinantes. Há mais facilidade para aceitar as estratégias em casos de risco de morte, caindo-se em uma concepção sanitária médico-centrada e de atenção à doença.

Não vêm sendo referidos atores políticos que possam ressignificar a categoria direitos de cidadania, com exceção do Ministério Público. Tal fato é explicado pelos profissionais por ser a área da fronteira, especialmente Foz do Iguaçu, considerada sem lei e dominada pelos donos do poder. As regulações institucionais frágeis e os gestores públicos do poder executivo não têm autonomia e hegemonia para denunciar desmandos que ocor- 
rem. O mix público e privado parece ser a regra nos encaminhamentos relativos aos direitos, especialmente porque os interesses econômicos particularistas são encontrados nos três países fronteiriços.

No âmbito da densidade institucional, verificou-se que os sistemas de saúde dos quatro países estudados são extremamente heterogêneos quanto à forma de organização, de gestão, de financiamento, do modelo de atenção e dos princípios ético-políticos. As diferenças e discrepâncias entre o arcabouço jurídico-institucional desses países apresentam-se como uma questão central a ser pensada na perspectiva de uma futura harmonização ou integração dos sistemas de saúde, sendo o forte determinante do trânsito interfronteiras.

\section{Direito à saúde e propostas institucionais recentes}

Quanto ao terceiro objetivo proposto, que foi o de produzir conhecimento que subsidiasse as decisões quanto à proteção social da saúde na região de fronteira do MERCOSUL, buscando favorecer o alcance da integração social e não unicamente econômica, além dos resultados já indicados anteriormente, podem ser acrescidos os aspectos a seguir enfocados.

Foi registrada a inserção da questão da fronteira em agendas governamentais atuais, destacando-se uma iniciativa de integração de fronteira partindo-se de ações concretas. Destaca-se, assim, nas cidades gêmeas Dionísio Cerqueira, Barracão e Bernardo de Irigoyen, uma proposta em execução recente, a seguir, detalhada. Os gestores dos três municípios vêm implantando ações de qualificação de recursos humanos, uso compartilhado do Laboratório de Fronteira (com divisão de responsabilidades e de recursos financeiros), Seminários de Integração e atividades de educação em saúde. Igualmente, na fronteira de Santa Catarina com a Província de Misiones, os gestores estaduais estão organizando encontros sistemáticos, tendo já um documento intitulado Carta de Posadas, de 14 de abril de 2004, no qual estabelecem metas a serem alcançadas em curto, médio e longo prazo em todas as áreas da administração. No setor de saúde, as propostas estão relacionadas à definição do nível de complexidade dos hospitais da linha da fronteira e à organização de um sistema com informações partilhadas para subsidiar a tomada de decisões e desenvolver sistemas de educação a distância para qualificação de pessoal 7. Em fevereiro de 2005, foram reiterados os propósitos de integração, ampliando-se as linhas de cooperação 8 . Convém destacar que já tinha havido uma ten- tativa de integração entre os dois governos em 1996, que não obteve sucesso.

O governo paraguaio incluiu, em sua proposta de agenda nacional para a saúde, ações integradoras direcionadas especificamente para a linha de fronteira, com ênfase nos seguintes itens:

"Análisis de la situación de salud de las regiones fronterizas de los países miembros del MERCOSUR y Estados Asociados; Elaboración de políticas sanitarias comunes con sus estrategias para lograr los objetivos; Planificación conjunta de las acciones priorizadas en el marco de la política nacional de cada país con acciones integradoras para los Estados Partes; Involucramiento y empoderamiento de los actores sociales de los tres niveles, local, regional y nacional para el análisis situacional y proponer soluciones a los problemas de salud en las personas y de los factores de riesgo que puedan afectar la salud humana; Acordar en el modelo de atención a ser implementado en las fronteras, priorizando las acciones dirigidas a la madre y el niño; Diseñar un instrumento común para la evaluación de necesidades de salud por municipios fronterizos; Implementación de las normativas del MERCOSUR en las fronteras en lo que hace relación a los ejes temáticos y evaluación de los compromisos asumidos; Elevar a consideración de los Señores Ministros de Salud del MERCOSUR y Países Asociados el tema 'Sistema de Integración de Salud en las Fronteras' para su análisis y directrices; Conformar un grupo técnico cuatripartito para las negociaciones y seguimiento del tema designado por los Señores Ministros y solicitar el apoyo técnico de la OPS/OMS" 9.

\section{Comentários conclusivos}

Identifica-se, cada vez mais, a perversa interface entre a crescente exclusão social e a saúde, acentuando a dificuldade da proteção pública no setor, o que exige não apenas investimentos e ações relacionados à proteção social, mas um debate intensivo sobre os novos direitos, sobre uma cidadania social globalizada, fazendo eco à globalização econômica.

A questão que mais se destacou, tendo em vista os resultados, tanto entre os gestores como entre os profissionais de saúde, foi a diversidade de compreensão sobre o significado do direito à saúde na região, o que ocasiona perfis distintos de atenção às demandas de saúde por parte dos estrangeiros que vivem na linha de fronteira. Essa constatação parece indicar dois fatores interligados: o primeiro, a inexistência de princípios ético-políticos comuns, decorrentes da política nacional de saúde; o segundo, níveis de institucionalidade frágeis, incapazes de absorver a de- 
manda dos usuários não brasileiros protegidos pelo Estatuto do Estrangeiro.

As práticas políticas, em alguns municípios, mantêm um padrão personalista e patrimonialista, com a oferta dos serviços e ações de saúde aos não brasileiros fundamentadas em critérios que se afastam das necessidades de saúde, diversos de região para região e mesmo de município para município. Tais procedimentos se repõem ao longo da linha de fronteira, ocasionando uma atenção desigual e perversa em alguns casos. Os usuários não brasileiros utilizam estratégias arriscadas para acesso ao sistema como, por exemplo, aguardar o agravamento da doença para o ingresso como emergência, quando o atendimento é sempre realizado.

Verificou-se, ainda, que os acordos e pactos firmados entre os governos dos países que integravam o MERCOSUL, à época, ou seja, a Argentina, o Brasil, o Paraguai e o Uruguai, não têm tido repercussão, inclusive em alguns casos com o desconhecimento completo acerca deles pelos gestores e profissionais. Do lado da população estrangeira que tem acesso ao sistema de saúde no Brasil, permanece a incerteza constante quanto ao tipo de atendimento que receberá em caso de necessidade. Do lado brasileiro, evidencia-se a inexistência de padrões uniformes de atenção, favorecendo decisões pessoais dos gestores e profissionais de saúde, e, conseqüentemente, dificultando o planejamento de ações integradas entre os sistemas de saúde dos municípios brasileiros e de outros países.

Considerando-se a realidade estudada, acredita-se que a diversidade de atenção à saúde na linha de fronteira do MERCOSUL pode ser explicada pelo reduzido nível de institucionalidade dos sistemas municipais de saúde, especialmente nas cidades gêmeas, onde se acentuam os processos de exclusão social em saúde aos usuários não brasileiros 10. Tais distinções acentuam as disparidades regionais ao longo da fronteira, ampliando a exclusão social em saúde e revelando as dificuldades de integração entre os sistemas locais de saúde nacionais e dos países vizinhos.

A garantia do acesso ao sistema de saúde, que expressaria o tipo de relação estabelecida entre a sociedade civil e o Estado, mantém-se em uma área nebulosa, em que a densidade institucional que favoreceria a sua garantia não ocorre. As referências dos profissionais, especialmente dos assistentes sociais, quanto à utilização de estratégias - criativas algumas vezes - para inclusão dos estrangeiros, concorrem para o atendimento pontual, não acarretando a questão da visibilidade, que imporia um debate público sobre os processos de inclusão no sistema de saúde. Convém lembrar que estratégias são recursos usados, como seu próprio nome indica, em situações especiais, que implicam um jogo de forças não condizentes com a desejada política pública de garantia de direito. Porém, se os profissionais não avançam, em termos discursivos, além de uma cidadania nacional, um forte compromisso ético com a vida é verificado em grande parte dos respondentes, traduzindo subjetivamente uma concepção de cidadania que ultrapassa os limites territoriais brasileiros. Pode-se afirmar que esse é um relevante ponto de partida para a discussão da universalização do direito à saúde.

As conclusões sinalizam o necessário aprofundamento das referências teóricas recentes sobre harmonização da atenção à saúde nos blocos regionais e o relevo que adquirem os conhecimentos sobre os sistemas de valores, ou seja, o patamar de solidariedade que se quer alcançar, visto que as distinções entre os países são gritantes. Nessa linha, pode-se afirmar que as diferenças repousam não apenas no acesso aos serviços e ações de saúde, mas igualmente na qualidade de vida da população, com reflexos imediatos no bem-estar e na saúde. Assim, a discussão sobre o alcance dos direitos é o ponto de partida para a harmonização efetiva, pois se reconhece que, contraditoriamente, os processos de integração regional colocaram em cheque as evidências do direito à saúde como um direito limitado à idéia de nacionalidade, de uma cidadania construída sobre o Estado-nação. É necessário ampliar o debate no sentido de entender que, atualmente, os processos “...que ceñían la moderna estructura burocrática del Estado nación se difuminan y los elementos que tradicionalmente lo explicaban - la idea de soberanía, territorialidad y poder-comienzan a ser discutidos y cuestionados" ${ }^{3}$. 


\section{Resumo}

Apresenta-se parte das conclusões do estudo realizado na fronteira entre o Brasil e países do MERCOSUL, e identificam-se os perfis de atenção que evidenciam a diversidade ética e política na fruição do direito à saúde, com a caracterização das demandas e as respostas dos sistemas locais. A base empírica foi a garantia ou não do acesso às ações e aos serviços de saúde pelos usuários não brasileiros. Para a coleta de dados, aplicaram-se formulários nos municípios com mais de 10 mil habitantes, registro em diários de campo, reuniões e entrevistas. O destaque foi a diversidade de compreensão sobre o significado do direito à saúde, indicando dois fatores: inexistência de princípios éticos e políticos comuns e níveis de institucionalidade frágeis, incapazes de absorver a demanda dos usuários não brasileiros. Verificou-se que os acordos entre os governos nacionais não têm tido repercussão, ocorrendo desconhecimento pelos gestores e profissionais. Na população estrangeira, permanece a incerteza quanto ao atendimento. No Brasil, evidencia-se a inexistência de padrões uniformes de atenção, favorecendo decisões pessoais dos gestores e profissionais de saúde, dificultando as ações integradas.

Direitos à Saúde; Necessidades e Demandas de Serviços de Saúde; Áreas de Fronteira; Política de Saúde

\section{Colaboradores}

V. M. R. Nogueira participou da concepção, elaboração e revisão final do texto apresentado. K. Dal Prá colaborou especialmente na coleta, na análise dos dados e na discussão dos resultados. S. Fermiano colaborou na revisão de literatura, redação do artigo e coleta de dados.

\section{Referências}

1. Feldmann S. As segregações espaciais da prostituição feminina em São Paulo. Revista Espaço e Debates 1990; 28:59-66.

2. Ministério da Integração Nacional. Proposta de reestruturação do Programa de Desenvolvimento da Faixa de Fronteira. Brasília: Ministério da Integração Nacional; 2005.

3. Gonzáles CL. La frontera en debate: una discusión abierta en torno a la integración regional y el futuro del Estado nación. In: Anais do Seminário Latino-americano Fronteira MERCOSUL: as interfaces entre o social e o direito à saúde [CD-ROM]. Florianópolis: Núcleo de Estudos Estado, Sociedade Civil e Políticas Públicas, Departamento de Serviço Social, Universidade Federal de Santa Catarina; 2005.

4. Brasil. Lei no. 907 de 21 de novembro de 2003. Prevê a igualdade de direitos entre brasileiros e uruguaios. Diário Oficial da União 2003; 24 nov.
5. Brasil. Lei $\mathrm{n}^{\circ} .6 .815$ de 19 de agosto de 1980, que define a situação jurídica do estrangeiro no Brasil. Diário Oficial da União 2003; 21 ago.

6. Gallo E. SIS-MERCOSUL: uma agenda para a integração [Introdução]. In: Gallo E, Costa L, organizadores. SIS-MERCOSUL: uma agenda para a integração. Brasília: Organização Pan-Americana da Saúde/Ministério da Saúde; 2004. p. 17. (Série Técnica: Projeto de Desenvolvimento de Sistemas e Serviços de Saúde, 9).

7. Secretaria Executiva da Articulação Internacional. Relatório do Encontro de Posadas. Posadas: Secretaria Executiva da Articulação Internacional; 2004.

8. Secretaria Executiva da Articulação Internacional. Relatório do Encontro de Florianópolis. Florianópolis: Secretaria Executiva da Articulação Internacional; 2005. 
9. Recalde HG. Política de salud - Paraguay. In: Anais do Seminário Latino-americano Fronteira MERCOSUL: as interfaces entre o social e o direito à saúde [CD-ROM]. Florianópolis: Núcleo de Estudos Estado, Sociedade Civil e Políticas Públicas, Departamento de Serviço Social, Universidade Federal de Santa Catarina; 2005.
10. Organización Panamericana de la Salud. Apoyo para planear investigaciones sobre estratégias para extender la protección social en salud. http:// www.opas.org (acessado em 12/Fev/2003).

Recebido em 14/Jun/2006

Versão final reapresentada em 02/Fev/2007 Aprovado em 13/Fev/2007 